Research Article

\title{
Process Automation of Chiller Plant for Welding Sub-Assembly
}

\author{
Vaibhav V. Kulkarni*, Kaustubh Joshi, Vishwesh Kugaonkar, Prasad Honrao and Aditya Patki
}

${ }^{1}$ Mechanical Engineering, MIT College of Engineering, Pune, India

Accepted 02 March 2016, Available online 15 March 2016, Special Issue-4 (March 2016)

\begin{abstract}
In order to join parts successfully in a robotic welding application, individual parts must be aligned precisely and held securely in place while the welding is proceeding. An important consideration, then, is the design of a fixture which holds the individual parts in the proper alignment. The tool must allow for quick and easy loading, it must hold the parts in place securely until they are welded together and must allow the welding gun unrestricted access to each weld point. However, loading and unloading stationary jigs of the robot cell can be time consuming and impractical. It is often more efficient to have two or more fixtures on a revolving workpiece positioner, despite a higher initial cost. With a revolving table for instance, the operator can load and unload while the robot is welding. Obviously, this speeds up the process and keeps the robot welding as much of the time as possible.
\end{abstract}

Keywords: Manipulator, design, automation, fixtures, positioners, welding.

\section{Introduction}

\subsection{Need}

We need to develop improved welding process control and automation techniques considering current international concerns about the restricted availability of skilled welders, the increasing need to improve occupational health and safety both in the workshop and general environment, pressure to improve productivity and reduce cost and the need to maintain joint integrity in critical structures. The shortage of skilled welders has been highlighted in the media; for example The Wall Street journal reviewed the problem in 2006 indicating a major shortage of welders and escalating weekly earnings. The same article claimed that on current estimates demand for skilled welders in the USA will outstrip supply by 200000 by 2010 . This is by no means an isolated problem; it has be reported as an international problem in countries such as Japan, and Australia as well as in Western Europe. There is believed to be a link between the perceived OH\&S hazards associated with welding and the ability to recruit new welding personnel. OH\&S is an issue which must be addressed due to our moral responsibility to welders and society in general as well as the recent and sometimes ill-conceived spate of litigation which often exploits our lack of technical knowledge concerning the physical effects of welding hazards. In terms of cost and productivity it is known

*Corresponding author: Vaibhav V. Kulkarni that in most common welding operations (on plain carbon steel) labour accounts for 70 to $80 \%$ of the total welding cost. Since labour costs are escalating, and will inevitably do so even in developing economies, total fabrication costs will increase accordingly. Productivity improvements are difficult to envisage in such a labour intensive, highly skilled and OH\&S affected environment. So how can we use technology to radically change this seemingly endless cycle? I would suggest that all the tools we need are either available. By application of current and emerging developments we can:

1.Reduce skill requirements

2.Enhance training

3.Improve $\mathrm{OH} \& \mathrm{~S}$

4.Improve productivity

5.Reduce cost

6.Improve quality

A part of this automation involves design and building of a manipulator to hold the components. In industrial ergonomics a manipulator is a handling assist device used to help workers lift, maneuver and place articles in process that are too heavy, too hot, too large or otherwise too difficult for a single worker to manually handle.. A good example would be a turn-tilt table that can maneuver components as per requirement.

Such manipulators can replace existing manual handling techniques. The conventional techniques tend to be time consuming and laborious. This in turn increases the production time of the products by reducing handling time or product downtime. 


\subsection{Objective}

1. Making the process simple.

2. Ensuring skilled labours are not required.

3. Consistency conforming to weld aesthetics and deposition rate.

4. Increasing production rate by inclusion of positioner fixtures.

5. Increasing production rate.

6 . Reducing time required for handling

\subsection{Scope}

This project could be the reformation in the current manufacturing process of the company since the processes are still carried out manually and there is vast scope for automated manufacturing processes by incorporating robotic arm welding and a fully automated assembly line could be possible in the near future.

Table 1: Degrees of welding automation

\begin{tabular}{|c|c|c|c|}
\hline Designation & \multicolumn{3}{|c|}{ Movement/Working } \\
\hline & $\begin{array}{c}\text { torch/workpiece } \\
\text { control }\end{array}$ & $\begin{array}{c}\text { filler wire } \\
\text { feeding }\end{array}$ & $\begin{array}{c}\text { workpiece } \\
\text { handling }\end{array}$ \\
\hline $\begin{array}{c}\text { Manual } \\
\text { welding }\end{array}$ & Manually & manually & manually \\
\hline $\begin{array}{c}\text { partially } \\
\text { mechanised } \\
\text { welding }\end{array}$ & Manually & mechanically & manually \\
\hline $\begin{array}{c}\text { fully } \\
\text { mechanised } \\
\text { welding }\end{array}$ & mechanically & mechanically & manually \\
\hline $\begin{array}{c}\text { automatic } \\
\text { welding }\end{array}$ & mechanically & mechanically & manually \\
\hline
\end{tabular}

\section{Literature survey}

Welding positioning equipment and machines systems are the backbone of fixed welding automation usually including welding lathes, turntables, positioners, circle welders and longitudinal seam welders. Tank welding equipment such as weld manipulators matched with pipe and tank turning rolls. These systems are available from the automation welding machine integrators individually as well as complete automatic welding systems that can be purchased as a turnkey system. Welding systems can be equipped with interchangeable fixtures so that one welding machine can do a variety of different parts.

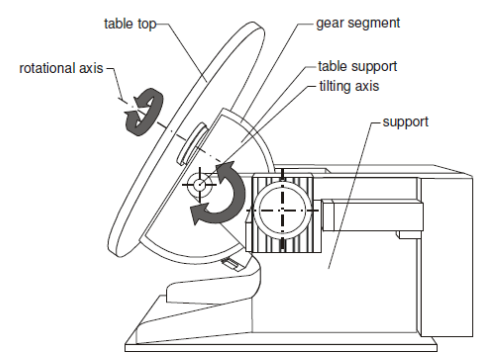

Fig 1. Turn Tilt Table

\section{Existing Process}

It can be seen from the process flow chart that the assembly needs to be rotated eight times over the period of the complete assembly welding process. Currently an overhead crane from the workshop is used for this rotation. For each iteration the crane is first moved to the desired location. Then the lifting belts are attached to the chiller assembly. After this attachment the crane is used carefully to rotate the assembly by lifting the belts from one side thus rolling the assembly over the belts. In the end the belts are removed. This entire process takes upto ten to fifteen minutes. So over the course of complete assembly for eight rotations it takes upto two hours. It also requires workers to be trained using the crane with precision and cannot to controlled by a novice worker.

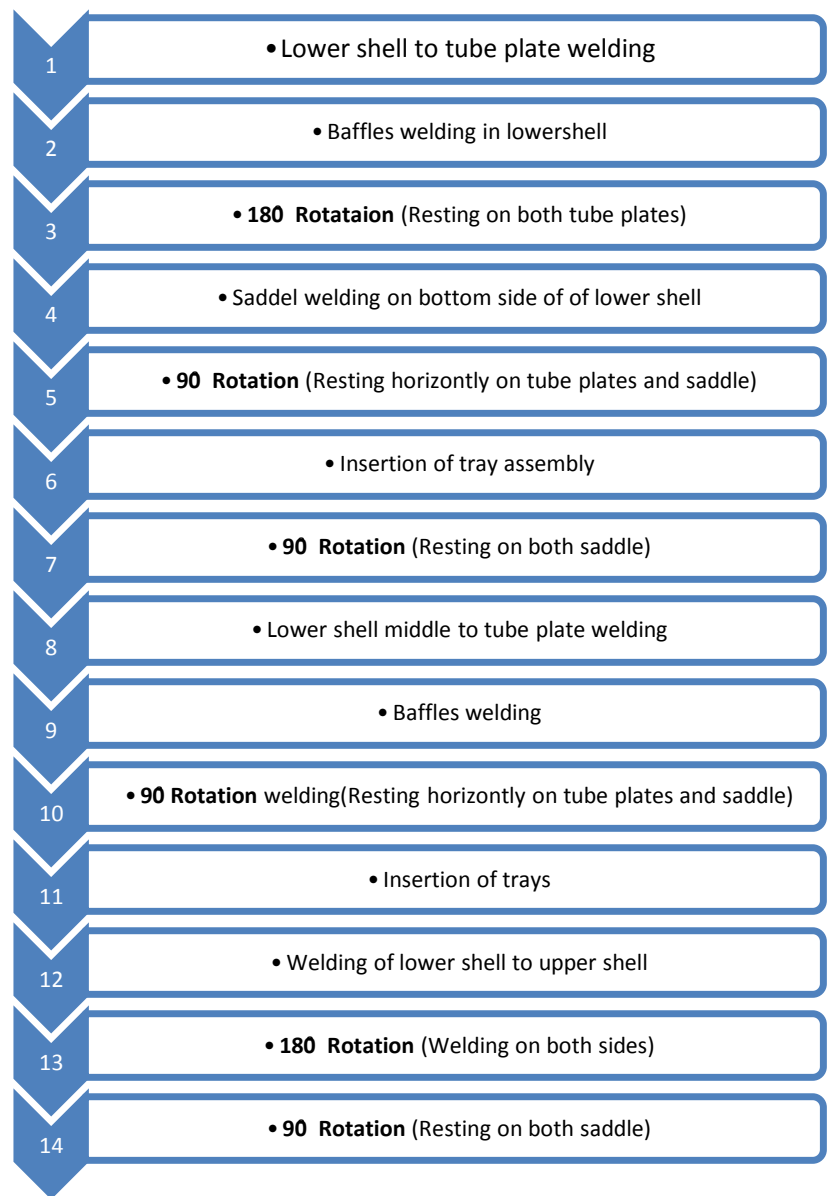

\section{Manipulator}

Manipulator mainly consists of a fixed holder and a moving holder. Two holders carry holding plates provided with T-slots. Moving holder can be moved longitudinally to accommodate different length chillers. For moving the moving holder the rail guides actuated by the screw drive mechanism is used. For supporting the chiller from middle section the hydraulic bed actuated by hydraulic cylinder is used. Other subassemblies consists of gear boxes, motor, bearing with holders, shafts, coupling, etc 


\subsection{Fixed Holder}

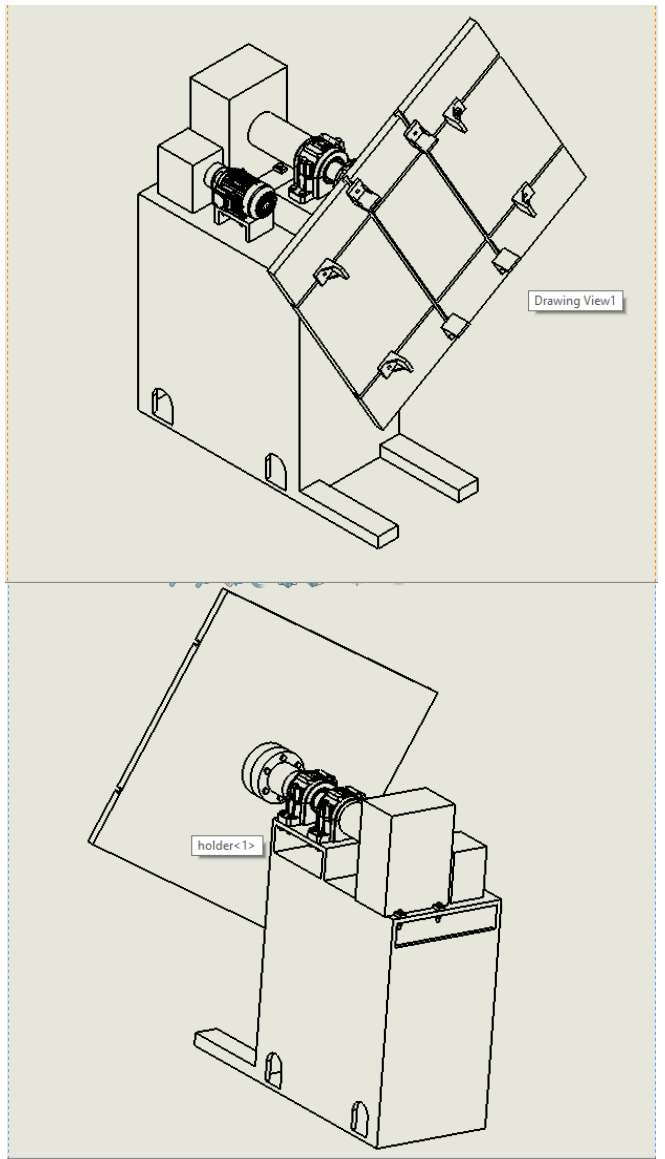

Fig 2. Fixed Holder

\subsection{Moving Holder}

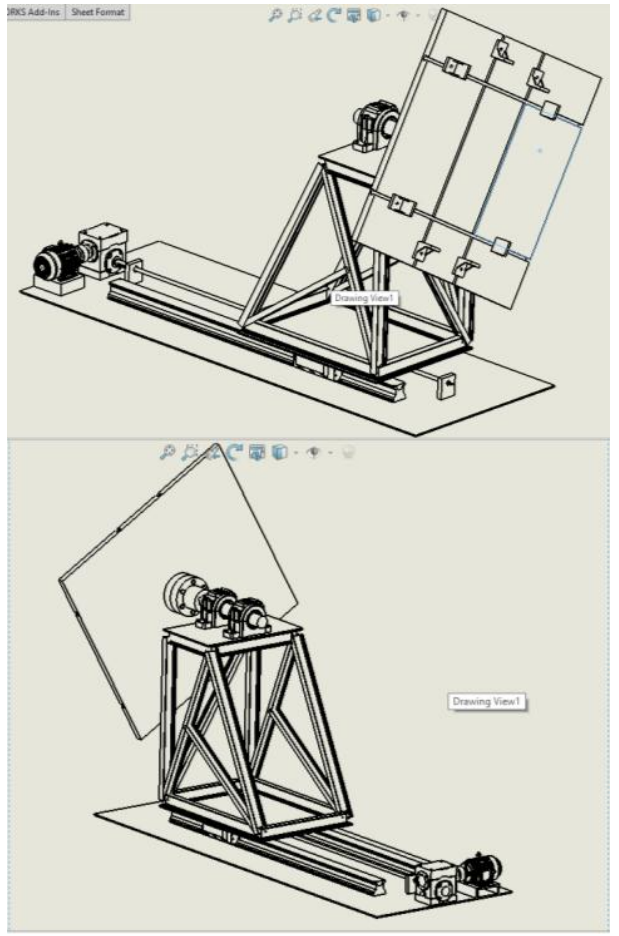

Fig 3. Moving Holder

\subsection{Hydraulic Bed}

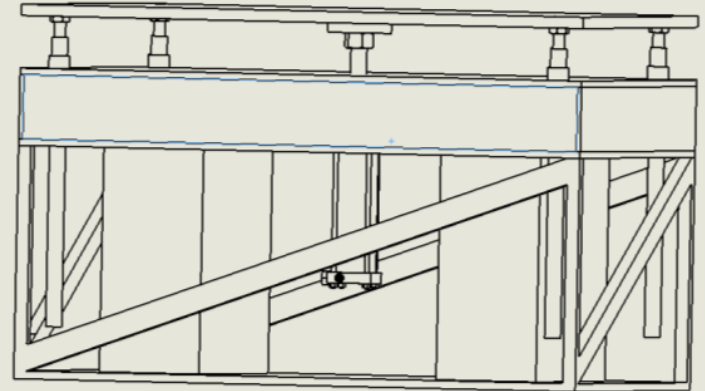

Fig.4 Hydraulic Bed

4.4 Motor And Gearbox

Torque And Power Calculations:-

$\mathrm{T}=\mathrm{I}^{*} \alpha$

$\omega=(2 * \pi * \mathrm{~N}) / 60$

$=\left(2 * \pi^{*} 0.2\right) / 60$

$\omega=0.0209 \mathrm{rad} / \mathrm{sec}$

$\alpha=(\delta \omega) /(\delta \mathrm{t})$

$\alpha=(020209 / 5)$

$\alpha=4.18 * 10^{\wedge}(-3) \mathrm{rad} / \mathrm{sec}^{\wedge} 2$

therefore,

$\mathrm{T}=\mathrm{w}^{*} \mathrm{~g}$ *offset of $\mathrm{CG}$

$\mathrm{T}=4000 * 9.81 * 0.2$

$\mathrm{T}=7848 \mathrm{~N}-\mathrm{m}$

$\mathrm{T}_{\text {inertia }}=1819.73 * 4.18 * 10^{\wedge}(-3)$

$\mathrm{T}_{\text {inertia }}=7.606 \mathrm{~N}-\mathrm{m}$

$\mathrm{T}_{\text {total }}=7855 \mathrm{~N}-\mathrm{m}$

SELECTION OF GEARBOX :

Input speed $=725 \mathrm{rpm}$

Gear ratio $=1: 3500$

Output speed $=0.21 \mathrm{rpm}$

Input power $=0.46 \mathrm{Kw}$

Output torque $=8520 \mathrm{Nm}$

Efficiency $=40 \%$

Final selection

Radicon Gear box

Model no: A2002

SELECTION OF MOTOR :

For $1 \mathrm{hp}$,

$1 \mathrm{Kw}=\mathrm{n}^{*} \mathrm{~m}^{*} 1.73^{*} \mathrm{U}^{*} \mathrm{I}^{*}(\mathrm{PF} / 1000)$

$$
=0.7 * 1.73 * 415^{*} 2.7 *(0.54 / 1000)
$$$$
=0.732 \mathrm{Kw}
$$

Final selection,

Compton Greave Motor, $1 \mathrm{Hp}$

Model- GD100L

\section{Conclusions}

1) By using manipulator production time is reduced by more than $50 \%$.

2) Weld quality is increased and reduces risk of misalignment.

3) The process increases the worker safety compared to conventional method. 
4) Skilled workers aren't required thus making process simple.

5) Serves basis for automation in welding.

\section{References}

Design of Welding Fixtures and Positiners-Prof. S.N.Shinde, Siddharth Kshirsagar, Aniruddha Patil, Tejas Parge, Ritesh Lomte

Martin. L. Culpepper, Design Of A Hybrid Positioner-Fixture For Six-Axis Nanopositioning And Precision Fixturing, MIT Dept. Of Mechanical Engineering, Massachusetts Avenue.

Reid. F. Allen, Design And Optimization Of A Formula Sae Race Car Chassis And Suspension, Massachusetts Institute of Technology, June 2009
Jeffery. J .Madden, Welding Fixtures And Active Position Adapting Functions, Dec 72007.

Colvin, F. H.; Haas, L. L. (1938). Jigs and Fixtures: A Reference Book. New York and

London: McGraw-Hill Book Company

Henriksen, E. K. (1973). Jig and Fixture Design Manual. New York, N.Y.: Industrial Press Inc.

Websites.

http://www.radicon.com/

http://www.cgglobal.com/

http://chestofbooks.com/crafts/machinery/Shop-Practice-

V1/Jigs-And-Fixtures.html

http://commons.wikimedia.org/wiki/File:Toggleclamp_m anual_horizontal_3D_opened_outline.png 